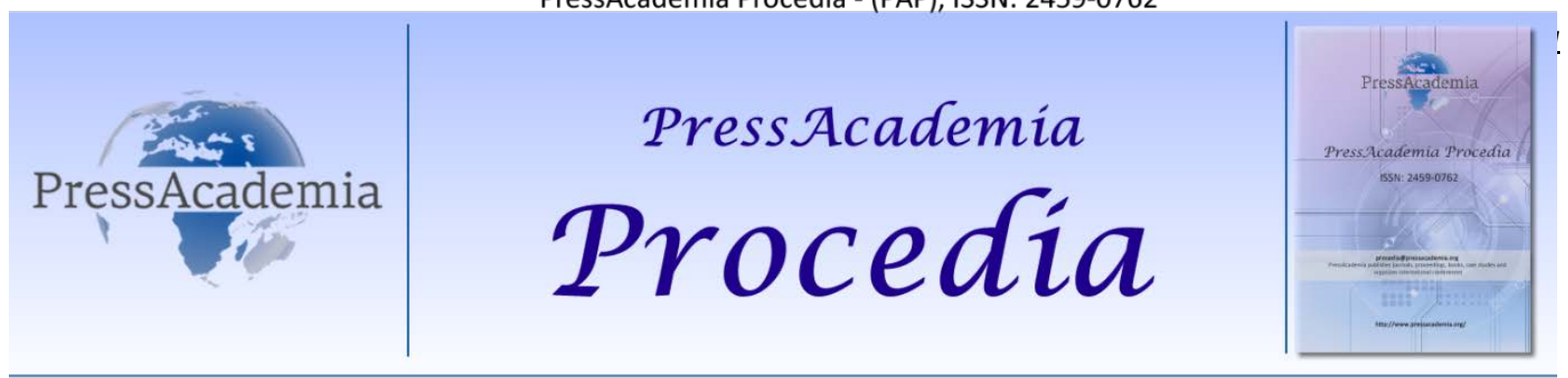

Global Business Research Congress (GBRC), May 26-27, 2016, Istanbul, Turkey.

\title{
RELATIONSHIP BETWEEN PERSONALITY TRAITS AND LEADERSHIP BEHAVIORS: A STUDY ON BUSINESS STUDENTS
}

\section{DOI: 10.17261/Pressacademia.2016118652}

\author{
Ozgul Orsal $^{1}$, Engin Karadag ${ }^{2}$ \\ ${ }^{1}$ Eskişehir Osmangazi Üniversitesi, oorsal@ogu.edu.tr \\ ${ }^{2}$ Eskişehir Osmangazi Üniversitesi, enginkaradag@ogu.edu.tr
}

\begin{abstract}
Today's changing environment, economic status and cultural structures affect the behavior of an individual and the personality traits in relation to these effects give direction to the leadership styles perceived in the society. In this context, the purpose of this study was to determine the relationship between personality traits and leadership behavior in business students. This study was modeled by using a correlational pattern. Data were collected from 386 business students studying at a faculty of management in a state university located in the Central Anatolia. All data were collected by using "Leadership Style Scale" developed by Northouse (2004) and "Five-factor Personality Scale" developed by Goldberg (1992). The leadership characteristics of the students were evaluated only by observation not by self-report. Style scale of Northouse suggests that lieders have two types of leadership behavior: task behavior and relationship behavior. Even, the focus of the style approach is that how the individual combines these two types of behavior in order to influence other people. After informin about the aim and subject of the study followed by obtaining verbal consent, pre-prepared questionnaire forms were filled out by the students under supervision in about 15-20 min. In the Leadership Style Scale, mean task-style score was 38.0 0 7.0; relationship-style score was $39.5 \pm 8.3$ and general leadership-style score was $78.0 \pm 14.3$. This findings reveal moderately high task-style and relationship-style scores and significantly high general leadership-style scores. In the Five-factor Personality Scale, mean sociability score was $31.5 \pm 6.1$, responsibility score was $37.9 \pm 6.5$, emotional balance score was $35.5 \pm 6.5$, adaptability score was $31.0 \pm 7.2$ and openness to improvement score was 34.6 \pm 5.3 . Both task-style and relationship-style leadership scores increased with increasing emotional balance personality scores. On the other hand, only relationship-style leadership score was found to increase with increasing responsibility, adaptability and openness to improvement personality scores $(p<0.01)$. There was a significant correlation with increasing scores in Leadership Style scores and increasing five-factor personality scores of "sociability, responsibility, emotional balance and openness to improvement" Leadership scores increased with the increasing age, while status of having education about leadership increased with the decreasing age. In students with no education about leadership, both general score and two subscores of leadership style scale as well as the "sociability, responsibility, emotional balance and openness to improvement" subscores of personality scale was increased. The goodness of fit of the theoretical model was determined by GFI, AGFI, RMSEA, $\chi^{2}$ ve $\chi^{2} / d f$ ratio. The correlation level of the covariate and the variance commonly explained by the model was GFI 0.97. AGFI goodness of fit value was 0.96 and similar to the GFI. Thus, GFI and AGFI goodness of fit values suggest that theoretical model is appropriate for the data set. On the other hand, RMSEA consisting of the variance unexplained by the model and covariance average was found to be 0.06 which suggest that only a few variance or covariance could not be explained by the theoretical model. In the model, the variance explained in each potential variable can be determined by its relationship with other potential variables. Thus, the variance explained in each potential variable and unexplained variances, in other words, the error value is not considered as a part of the measurement model but as of the structural model. In this study, $\chi^{2} / d f$ ratio was 2.37 , suggesting a good fit between observed and multiplied covariance matrices. According to the SEM, personality trait increases leadership style score by 8.78 points. Style approach underlies the leadership behavior, which differentiate it from the personality approach focusing on the personality traits and the skills approach focusing on the abilities of leader. Style approach provides a key frame to evaluate leadership behavior properly with the task and relationship dimensions. Leadership behaviors can be acquired or developed by having knowledge about this frame. Because determining the perceptions of business students about the personality traits and leadership behaviors will shed light on the future leadership concepts, this study will have a major contribution to the literature. Results of the present study suggest that personality traits influence the leadership behaviors. Future studies should find the similarities and differences between these influences. Determination of the personality traits and perceived leadership behaviors will be beneficial in directing the human power and solution of our problems.
\end{abstract}

Keywords: Leader, leadership style, personality, sociability, responsibility, emotional balance, adaptability, openness to improvement 


\section{KişiLiK ÖZELLiKLERi VE LiDERLiK DAVRANIŞLARI iLIŞKisi: işLETME ÖĞRENCiLERI ÜZERINE BíR ARAŞTIRMA}

\section{ÖZET}

Günümüzde değişen çevre, ekonomik durum, kültür yapılarının bireylerin davranışlarını etkilediği ve bu etkilerle oluşan kişilik özelliklerinin toplum içindeki algılanan liderlik stillerine yön verdiği bilinmektedir. Bu kapsamda bu çalışmanın amacı; işletme öğrencilerin kişilik özellikleri ve liderlik davranış eğilimleri arasındaki ilişkiyi belirlemektir. Korelasyonel desen kullanılarak modellenen bu çalışma bir üniversitesinin işletme bölümünde öğrenim görmekte olan 386 öğrenci ile tamamlanmıştır. Northouse (2004) tarafından geliştirilen “Liderlik Stil Ölçeği” ve Goldberg (1992) tarafından geliştirilen "Beş Faktör Kişilik Ölçeği” kullanılmıştır. Öğrencilerin liderlik davranışları gözleme değil beyana dayanır. Northouse' stil ölçeği liderlerin görev davranışları ve ilişki davranışları olmak üzere iki tür liderlik davranışı olduğunu öne sürer. Hatta başkalarını etkilemek için liderlerin bu iki tür davranışı nasıl birleştirdikleri stil yaklaşımının merkezi odak noktasıdır. Çalışmanın konusu ve amacı hakkında bilgilendirilen öğrenciler sözlü onamları alındıktan sonra, önceden hazırlanan anket formlar öğrencilerin sınıflarında gözlem altında kendileri tarafından dolduruldu. Işletme öğrencilerinin Liderlik Stil Ölçeğinin görev tarzı puan ortalaması $38.0 \pm 7.0$; ilişki tarzı puan ortalaması $39.5 \pm 8.3$ ve genel liderlik tarzı puan ortalaması ise $78.0 \pm 14.3^{\prime}$ tür. Bu bulgulara göre görev tarzı ve ilişki tarzı alt ölçeklerin liderlik puanları orta derecede yüksek iken genel liderlik tarzı puanı çok yüksektir. Beş Faktör Kişilik Ölçeğinin dışa dönüklük puan ortalaması $31.5 \pm 6.1$; sorumluluk puan ortalaması $37.9 \pm 6.5$; duygusal denge puan ortalaması $35.5 \pm 6.5$; uyumluluk puan ortalaması $31.0 \pm 7.2$ ve gelişime açıkık puan ortalaması ise $34.6 \pm 5.3^{\prime}$ dir. İşletme öğrencilerinin duygusal denge kişilik puanları arttıkça hem görev tarzı hem de ilişki tarzı liderlik puanları artmaktadır. Ancak sorumluluk, uyumluluk ve denge kişilik puanları arttıkça sadece ilişki tarzı liderlik puanları artmaktadır. Öğrencilerin liderlik stil ölçeğinden alınan puanlar arttıkça, beş faktör kişilik ölçeğinden "dışa dönüklük, sorumluluk, duygusal denge, gelişime açıklık" dan alınan puanların artması istatistiksel olarak anlamlıdır. (Herbiri için; $p<0.01$ ). Yaş arttıkça ilişki tarzı liderlik stili puanları artarken $(r=0,132, p<0.01)$, yaş azalırken liderlik eğitimi alma durumu artmaktadır $(r=-0.295, p<0.01)$. Liderlik eğitimi almayanlarda hem genel hem de alt boyutları olan liderlik stil ölçeğinden alınan puanlar ile beş faktör kişilik ölçeğinin alt boyutu "dışa dönüklük, sorumluluk, duygusal denge, gelişime açıkıı"tan alınan puanlar artmaktadır(Herbiri için; $p<0.01$ ). Geliştirilmiş olan teorik modelin uyum iyiliği; GFI, AGFI, RMSEA, $\chi^{2}$ ve $\chi^{2} / d f$ oranı ile belirlenmiştir. Kovaryansın bağıntı derecesini ve model tarafından ortaklaşa açıklanan varyansı GFI; 0.97 olarak saptanmıştır. AGFI uyum iyiliği değeri GFl’e benzer olarak 0.96 olarak saptanmıştır. Bu sonuçta GFI ve AGFI uyum iyiliği değerleri, teorik modelin elde edilen veriye uygun olduğunun göstergesidir. Diğer taraftan, RMSEA, model tarafından açıklanamayan varyans ve kovaryans ortalamasını içermekte ve çalışmada ise RMSEA değeri, 0.06 olarak saptanmıştır. Bu durumda, sadece birkaç varyans ve kovaryansın, oluşturan teorik model tarafından açıklanmamış olduğunu göstermektedir. Modelde her bir gizil değişkende açıklanan varyans, diğer gizil değişkenler ile ilişkisi sayesinde belirlenebilmektedir. Bu nedenle, her bir gizil değişkende açıklanan varyans ve bunun sonucunda belirlenen açıklanamayan varyans yani hata değerleri ölçme modelinin değil, daha çok yapısal modelin bir parçası olarak kabul edilebilirler. Çalışmada $\chi^{2} / d f$ oranı, 2.37 olması gözlenen ve çoğaltılan kovaryans matrisleri arasında iyi bir uyumun göstergesi anlamına gelmektedir. Oluşturulan YEM sonucuna göre; kişilik özelliği liderlik stilini 8.78 puan arttırmaktadır. Stil yaklaşımı liderin davranışına vurgu yapar. Bu da onu liderin kişilik özellikleri üzerinde duran kişilik yaklaşımından ve liderin yetenekleri üzerinde duran beceriler yaklaşımından ayırt eder. Stil yaklaşımı davranışı görev ve ilişki boyutlarıyla değerlendirilerek liderliği geniş bir şekilde değerlendirmek için önemli bir çerçeve sunar. Bu çerçeve öğrenilerek liderlik davranışları edinilebilir ve geliştirilebilir. İşletme öğrencilerinin kişilik özellikleri ve liderlik davranışları ile ilgili algısı geleceğin liderliğini anlamamıza ışık tutacağı için literatüre önemli katkı sağlayacağı düşünülmektedir. Çalışmamızda kişilik özelliklerinin liderlik davranışı eğilimine etkisi olduğu tespit edilmiştir. Yapılacak yeni araştırmalarda bu etki düzeylerinin benzerlik ve farklılıkların bulunması önem taşımaktadır. Kişilik özellikleri ve algılanan liderlik davranışlarını belirlenmesi, ülkemizin insan gücünün yönlendirilmesi ve sonuçlarının değerlendirilmesi sorunlarımızın çözümünde etkili olacağı düşünülmektedir.

Anahtar Kelimeler: Lider, liderlik, liderlik tarzı, kişilik, dışa dönüklük, sorumluluk, duygusal denge, uyumluluk, gelişime açıklık

\section{GiRiş}

Allport 1937'de yayınladığı "Kişilik" kitabında kişiliği; "bireyin çevreye yapacağı uyumu belirleyen psiko-fiziksel sistemlerin, bireyin kendi içindeki dinamik organizasyonları" olarak tanımlamıştır. Allport'a göre, "insanın en ayırt edici özelliği onun bireyselliği"dir(Allport, 1921). Bireylerin fiziksel görünüşleri yanında değer ve davranışları da farkıııklar gösterir. Bunun birçok nedeni vardır. Kişiliğin tarifi zordur. Çünkü kişilik kavramı geniş perspektiftedir. Ancak kişi hakkında yargılara bu perspektiflerden varılmaktadır. Kişi çok çeşitli ve farklı düzeyde özelliklere sahip olduğundan, bu niteliklerin hepsini bir arada ölçmek mümkün değildir.(Tatlııoğlu, 2014). Bu özellikler çevreden öğrenilebilir, kendilerini geliştirerek kazanılabilir ve verilen eğitimlerle geliştirilebilir. Doğuştan başlayan ve kendilerini buldukları güne kadar geçen süreye kadar belirli kişilik özellikleri edinirler.

Kişinin tutum ve davranışları kendisine ait olduğu kadar çevresinde etkisiyle biçimlenmektedir (Inanç \& Yerlikaya, 2008). İ̧̧inde bulunulan durumun davranışlarımızı nasıl etkilediği ve davranışların kişiyi nasıl yansıttığıdır (Berger 2006 akt. Inanç \& Yerlikaya 2008). 
Kişinin yansıttı̆̆ı tutum ve davranışlar çevre, kültür ve ekonomik yapılarda etkilenir. Bu etkilerle oluşan kişilik özellikleri toplum içindeki algılanan liderlik stillerinin nasıl algılandığında büyük rol oynar. Özellikle liderliğin çalışma yaşamındaki önemine iliş־kin kabul gören anlayış, araştırmacıların lider olarak algılanmayı açıklama ve daha iyi liderleri seçme süre־cine katkı sağlamaları yönünde beklentilere neden ol־maktadır(Hogan, Curphy, \& Hogan, 1994).

Liderlik kavramı ise insanlık tarihi boyunca var olan çok eski bir kavram olup, 1920'li yılların başından itibaren bilime konu olmuştur. Günümüze kadar çok sayıda tanım yapılmış olmasına rağmen, henüz üzerinde fikir birliğine varılmış bir tanım geliştirilememiştir(Bakan \& Büyükbeşe, 2010; Bass, 1990). Liderlik, farklı bakış açılarından hareketle incelenen(Hodgetts, 1999), farklı kişiler tarafından farklı anlamlar yüklenen bir süreç(Cook, Hunsaker, \& Coffey, 1997; Koçel, 2001; Werner, 1993) (Paksoy, 2002) olarak ele alınmaktadır(Çelik \& Sünbül, 2008). Öncelikli olarak araştırmalar liderin taşıdığı özelliklerin belirlenmesine yönelik olarak yapılmıştır. Sonrasında liderin özellikleri yerine nasıl davrandığı üzerinde durulmuş ve devamında liderin davranışının farklı koşullarda nasıl değiştiği araştırılarak durumsal faktörlerin daha önemli olduğu belirlenmiştir(Özmen, 2009).

Literatürde liderlik konulu birçok çalışma gerçekleştirilmiş, farklı liderlik yaklaşımları geliştirilmiş ve işletmenin amaçlarına ulaşmada nasıl bir liderlik tarzının daha verimli olacağı sorusuna çeşitli yönlerden cevap aranmıştır(Taslak, 2008). Stil yaklaşımı liderin davranışına vurgu yapmaktadır. Genel olarak liderin ne yaptığı ve nasıl hareket ettiğine odaklanır. Araştırmacılar stil yaklaşımını görev odaklı ve ilişki odaklı liderlik stili şeklinde iki ana başııtan oluştuğunu varsaymaktadırlar. Bu yaklaşımın ana hedefi, liderin görev odaklı ve ilişki odaklı davranışının astların amaca ulaşmak için gösterecekleri çabaları nasıl etkilediğini ortaya koymaktır. Stil yaklaşımını araştıran birçok çalışma yapılmıştır. Bunlardan bazıları The Ohio StateUniversity, TheUniversity of Michigan ve Blake ve Mountan tarafından yapılan çalışmalardır(Northouse, 2013).

Örgütsel davranış bilimcilerine göre liderlik, bir grup içerisinde yer alan bir bireyin yine grup içerisinde oynadığı role ve bu rolün diğer grup üyelerinin beklentilerini biçimlendirmesine dayanan karşılıklı etkileşim süreci içinde oluşmaktadır. Grup içerisinde gösterilen bu davranışların, bireyin kişilik özelliklerinin dışa vurulması ya da yansıması olduğu söylenebilir. Farklı kişilik özellikleri taşıyan bireyler belli durumlarda farklı davranışlar (tepkiler) sergileyebilirler(Burke \& Litwin, 1992).

Kişilik ve örgütsel davranış alanlarında yapılan araştırmaların verileri, kişiliğin bireyin davranışlarına yön veren en önemli etken olduğunu ve bu bağlamda hem örgütsel performansla(Barrick, Day, Lord, \& Alexander, 1991 ) hem de çalışanların tutumları ile ilişkili olduğunu ortaya koymaktadır. Kişilik ve örgütsel performans alanında yapılan araştırmalarda daha çok "Liderlik" boyutu üzerinde yoğunlaşımıştır. Kişiliğin liderlik tarzları üzerinde ne ölçüde etkili olduğu konusu hep ikinci planda kalmıştır.

$\mathrm{Bu}$ araştırma kişiliğin liderlik stilleri eğilimi üzerindeki etkisini araştırmayı amaçlamıştır. Yurtdışında yapılan kişilik ve liderlik ilişkilerini inceleyen çok sayıda araştırma olmasına karşın(Judge, Piccolo, \& Kosalka T., 2009; Kognor \& Nordvik, 2004; Strang \& Kunhert, 2009) ülkemizde kişilik ve liderlik stil davranışı arasındaki ilişkiyi araştıran çalışma sınırlı sayıda bulunmaktadır. Stil yaklaşımı liderin davranışına vurgu yapar. Bu da onu liderin kişilik özellikleri üzerinde duran kişilik yaklaşımından ve liderin yetenekleri üzerinde duran beceriler yaklaşımından ayırt eder. Stil yaklaşımı davranışı görev ve ilişki boyutlarıyla değerlendirilerek liderliği geniş bir şekilde değerlendirmek için önemli bir çerçeve sunar. Bu çerçeve öğrenilerek liderlik davranışları edinilebilir ve geliştirilebilir. İşletme öğrencilerinin kişilik özellikleri ve liderlik davranışları ile ilgili algısı geleceğin liderliğini anlamamıza ışık tutacağı için literatüre önemli katkı sağlayacağı düşünülmektedir.

Bu açıklamalar ışığında araştırmada, kişilik özelliklerinin liderlik davranışı (stillerine) eğilimi üzerine etkisinin olup olmadığı bu araştırmanın problemini oluşturmaktadır. Bu problemin çözümünde araştırmanın amacına uygun olarak geliştirilen aşağıdaki hipotez test edilip çözüm yolu araştırılacaktır.

H0: Kişilik ile liderlik tarzı, her ikisinin alt boyutları ve diğer değişkenler (cinsiyet, sınıf, yaş, liderlik eğitimi alma) arasında ilişki yoktur.

H1: Kişilik ile liderlik tarzı, her ikisinin alt boyutları ve diğer değişkenler (cinsiyet, sınıf, yaş, liderlik eğitimi alma) arasında ilişki vardır. 


\section{VERI VE YÖNTEM}

Çalışmanın uygulanabilmesi için gerekli görüşmeler yapılarak, çalışma ile ilgili bilgi verilmiş ve gerekli izinler alınmıştır. Araştırmaya katılan öğrencilerden, araştırmaya katılmaya gönüllü olduklarına ilişkin onay alınmıştır. Veri toplama aşamasında Helsinki Bildirgesindeki kurallara uygun olarak hareket edilmiştir.

Araştırmanın kuramsal evreni Osmangazi Üniversitesi İşletme Bölümü'nde öğrenim gören 410 adet lisans öğrencisidir. Evren içerisindeki öğrencilerin sınıflara göre dağılımı ise şu şekildedir; 1 . Sınıf ( $\eta=91, \% 22), 2$.nci $\operatorname{sınıf}(\eta=99, \% 24.1), 3 . n c u ̈ ~ s ı n ı f ~(\eta=87, \% 21.5), 4$.ncü sınıf $(\eta=133, \% 32.3)$.

Araştırmada örnekleme yöntemine başvurulmamış ve çalışmada evrenin tamamına ulaşılması hedeflenmiştir. Ancak bazı öğrencilere ulaşılamaması nedeniyle örneklem kapsamında değerlendirmeye alınan anket sayısı 386 olarak gerçekleşmiştir. Ankete katılan öğrencilerin sınıflara göre dağılımı ise şu şekildedir; 1. Sınıf ( $\eta=87, \%$

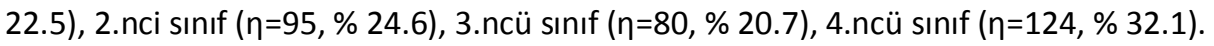

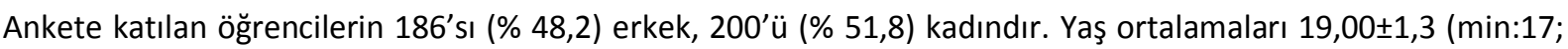
mak:22) yıldır. Katılımcıların sadece 84 'si $(\% 21,8)$ liderlik konusunda eğitim almıştır.

Araştırmada veriler anket yöntemiyle toplanmıştır. Anket üç bölümden oluşmaktadır ve ilk bölümünde ankete katılanların demografik bilgilerini belirlemeye yöneliktir. Anketin ikinci bölümünde, liderlik davranışlarını belirlemeye yönelik Northouse'dan uyarlanan "Liderlik Stil Ölçeği” kullanılmıştır. Ölçek toplam 20 sorudan oluşmakta ve göreve yönelik (tek sayılı sorular) ve ilişkiye yönelik (çift sayılı sorular) olmak üzere iki alt boyuttan oluşmaktadır. 45-50 "çok yüksek" aralıkta, 40-44 "yüksek" aralıkta, 35-39 "orta derecede yüksek" aralıkta, 3034 "orta derecede düşük" aralıkta, 25-29 "düşük" aralıkta, 10-24 "çok düşük" aralıkta olduğunu göstermektedir. 5’li likert tipi bir ölçektir. Liderlik Stil Ölçeği için Cronbach's alfa değeri 0.89 olarak bulunmuştur. Bu sonuç güvenilir katsayısına sahip olduğunu göstermektedir.

Görev için alınan puan başkalarına kendi rollerini tanımlamak ve kendilerinden ne beklendiğini bilmelerini sağlamak yoluyla ne derecede yardımcı olunduğunu gösterir. Bu faktör liderlik pozisyonunda iken görevyönelimli olma eğilimlerini tanımlamaktadır. i̇lişki için alınan puan astlarınızı kendileri, birbirleri ve grubun kendisi açısından rahat hissettirmek için gösterilen çabayı ölçmektedir. Bu faktör ise liderlik pozisyonunda iken ne kadar insan-odaklı olunduğunu tanımlamaktadır.

Anketin son bölümünde ise, çalışanların kişilik özelliklerini ölçmek için Goldberg "in 1992 yılında geliştirdiği “Beş Faktör Kişilik Ölçeği" yer almaktadır. Ölçek bireylerin kişilik özelliklerinin olumlu ve olumsuz yönlerini belirlemeye yönelik, toplam 50 sorudan oluşmaktadır ve beş faktör kişilik modelinde yer alan dışadönüklük (110), sorumluluk (11-20), uyumluluk (21-30), duygusal denge (31-40) ve gelişime açıklık (41-50) boyutlarının her birini ölçmektedir. 5'li likert tipi bir ölçektir. Beş Faktör Kişilik Ölçeğinin Cronbach's alfa katsayısı 0.82 olarak bulunmuştur. Bu sonuç güvenilir katsayısına sahip olduğunu göstermektedir.

\section{BULGULAR VE TARTIŞMA}

Veriler IBM SPSS (Versiyon 21) ve AMOS22 istatistik paket programında değerlendirildi. Analizler için MannWhitney $\mathrm{U}$ testi, Kruskal-Wallis testi, korelasyon analizi, yapısal eşitlik modeli kullanılmıştır. İstatistik anlamlılık değeri olarak $\mathrm{p}<0.05$ kabul edildi.

Tablo 1: Liderlik Stil ve Beş Faktör Kişilik Ölçeklerinin Normallik Dağılımı

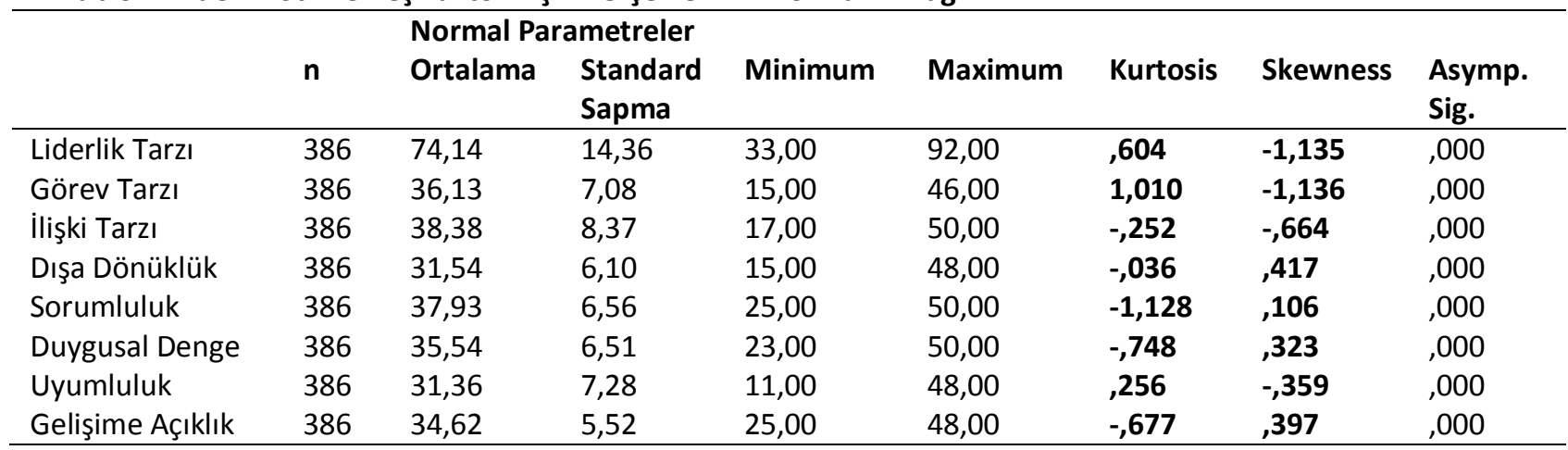

Tablo 1 incelendiğinde öğrencilerin "Stil Anketi”nden görev tarzı alt alanından aldıkları puan ortalaması $36,1 \pm 7,0$, ilişki tarzı alt alanından aldıkları puan ortalaması $38,3 \pm 8,3$, genel liderlik tarzı puan ortalaması $74,1 \pm 14,3^{\prime}$ tür. Kurtosis ve Skewness değerleri +1.5 -1.5 için olduğu zaman normal dağılım olduğu kabul 
edilmektedir (Tabachnick and Fidell, 2013) Eğer Kurtosis ve Skewness değerleri +2.0 -2.0 olduğu zaman normal dağılım olduğu kabul eden literatürde bulunmaktadır (George, D., \& Mallery, M. 2010) Bu değerlendirmeler ışığında Liderlik Stil ve Beş Faktör Kişilik Ölçeklerinin Normal dağıldığı görülmektedir. Ancak Shapiro-Wilk ve Kolmogorov-Smirnov değerlerine göre ölçeklerimiz normal dağılmamaktadır. Bu durumun nedeni beşli Likert tipi ölçek kullanıldığı için ayrıca sosyal bilimlerde daha fazla Kurtosis ve Skewness değerleri tercih edilmektedir(Tabachnick and Fidell, 2013, George, D., \& Mallery, M. 2010).

Tablo 2: Öğrencilerin Lider Stil Anketinden Aldıkları Puan Ortalamalarının Bazı Sosyo-Demografik Özelliklere Göre Dağılımı

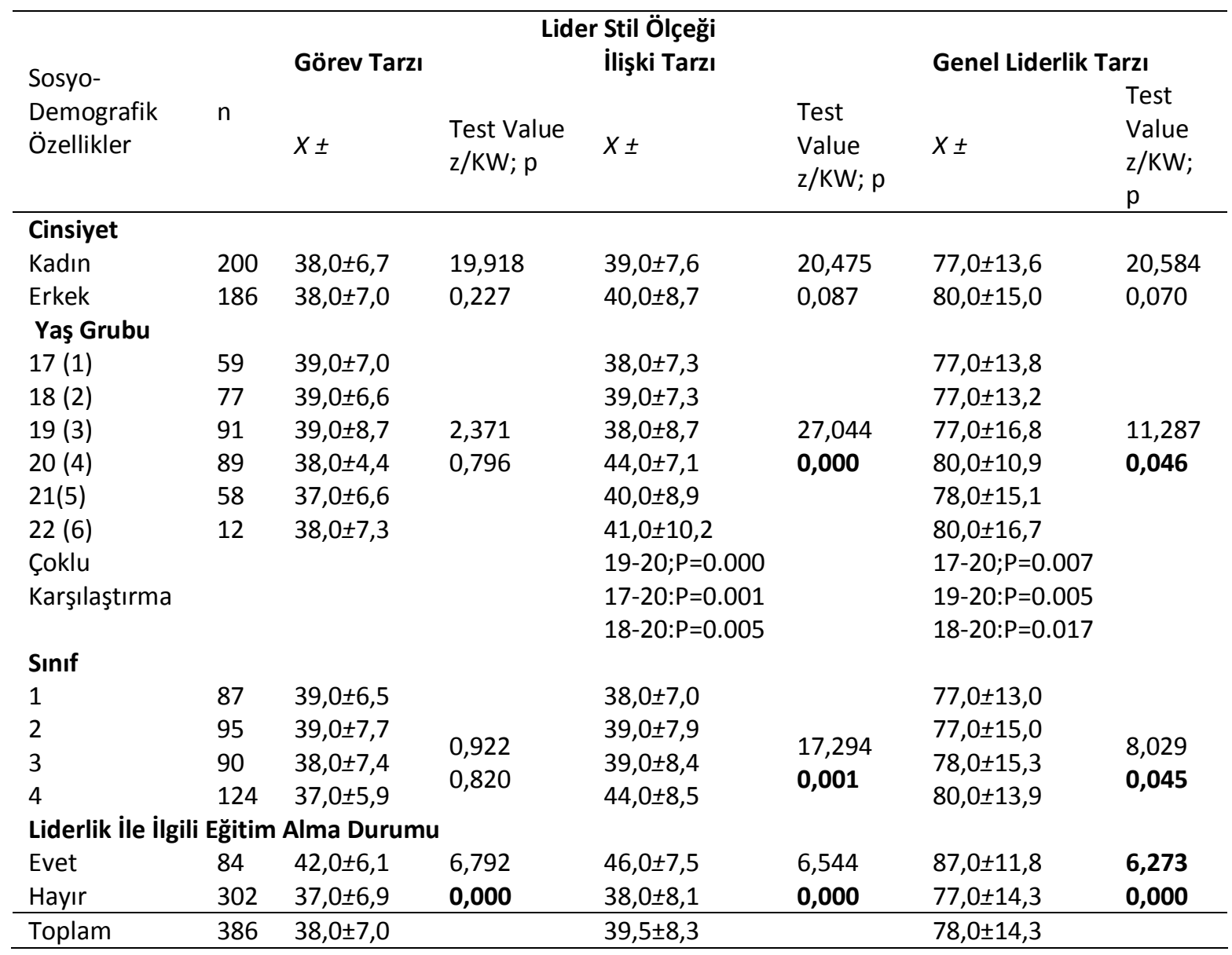

Tablo 2'de çalışma grubunu oluşturan öğrencilerin bazı sosyo-demografik özelliklerine göre Liderlik Stil Ölçeği'nden aldıkları puan ortalamaları dağılımı verilmiştir. Tablo 2 incelendiğinde, işletme bölümünde okuyan öğrencilerin 20 yaşında olanlar diğer yaş grubunda olanlara göre liderlik stil ölçeğinin alt faktörlerinden ilişki tarzı liderlik ve genel liderlik tarzı puanları yüksektir (her biri için; $p<0.05$ ). Liderlik ile ilgili eğitim alanların görev tarzı, ilişki tarzı ve genel liderlik stil ölçek puanları eğitim almayanlara göre daha yüksek olması istatistik olarak anlamlıdır(p<0.001). Ancak öğrencilerin liderlik stili ile cinsiyeti arasında anlamlı bir farklılık saptanamamıştır(her biri için; $(p>0.05)$. Çalışma grubunu oluşturan öğrencilerin bazı sosyo-demografik özelliklerine göre Beş Faktör Kişilik Anketi’nden aldıkları puan ortalamaları dağılımı Tablo 3'de verilmiştir. 
Tablo 3: Öğrencilerin Beş Faktör Kişilik Ölçeği'nden Aldıkları Puan Ortalamalarııın Bazı Sosyo-Demografik Özelliklere Göre Dağılımı

\begin{tabular}{|c|c|c|c|c|c|c|c|c|c|c|c|c|}
\hline \multirow[b]{3}{*}{$\begin{array}{l}\text { Sosyo- } \\
\text { Demografik } \\
\text { Özellikler }\end{array}$} & \multicolumn{7}{|c|}{ Beş Faktör Kişilik Ölçeği } & \multirow{3}{*}{ Uyumluluk } & \multirow[b]{3}{*}{$\begin{array}{l}\text { Test } \\
z / K W ; p\end{array}$} & \multirow[b]{3}{*}{ Value } & \multirow{2}{*}{\multicolumn{2}{|c|}{ Gelişime Açıklık }} \\
\hline & \multirow[b]{2}{*}{$\mathrm{n}$} & \multicolumn{2}{|c|}{ Dışa Dönüklük } & \multicolumn{2}{|c|}{ Sorumluluk } & \multicolumn{2}{|c|}{ Duygusal Denge } & & & & & \\
\hline & & $x \pm$ & $\begin{array}{l}\text { Test } \\
\text { Value } \\
\text { z/KW; p }\end{array}$ & $x \pm$ & $\begin{array}{l}\text { Test } \\
\text { Value } \\
\mathrm{z} / \mathrm{KW} ; \\
\mathrm{p}\end{array}$ & $X \pm$ & $\begin{array}{l}\text { Test } \\
\text { Value } \\
\text { z/KW; } \\
\text { p }\end{array}$ & & & & $x \pm$ & $\begin{array}{l}\text { Test } \\
\text { Value } \\
\mathrm{z} / \mathrm{KW} ; \mathrm{p}\end{array}$ \\
\hline Cinsiyet & & & & & & & & & & & & \\
\hline Kadın & 200 & $31,5 \pm 6,1$ & 17,963 & $38,4 \pm 6,4$ & 16,967 & $36,0 \pm 6,6$ & 17,084 & $32,5 \pm 7,0$ & 15,569 & & $35,0 \pm 5,3$ & 16,792 \\
\hline Erkek & 186 & $31,5 \pm 6,0$ & 0,561 & $37,9 \pm 6,6$ & 0,135 & $35,0 \pm 6,3$ & 0,166 & $30,1 \pm 7,3$ & ,006 & & $34,1 \pm 5,2$ & ,098 \\
\hline Yaş Grubu & & & & & & & & & & & & \\
\hline $17(1)$ & 59 & $31,4 \pm 5,4$ & & $37,9 \pm 6,4$ & & $37,1 \pm 6,6$ & & $33,3 \pm 6,3$ & & & $35,8 \pm 5,7$ & \\
\hline $18(2)$ & 77 & $29,7 \pm 5,5$ & & $36,4 \pm 6,4$ & & $33,8 \pm 6,2$ & & $32,1 \pm 6,2$ & & & $33,1 \pm 4,4$ & \\
\hline $19(3)$ & 91 & $31,7 \pm 5,5$ & 13,306 & $37,5 \pm 7,3$ & 12,659 & $34,0 \pm 5,6$ & 21,056 & $28,7 \pm 6,8$ & 24,669 & & $33,7 \pm 4,9$ & 31,924 \\
\hline $20(4)$ & 89 & $32,5 \pm 6,7$ & 0,021 & $38,4 \pm 5,7$ & 0,027 & $37,1 \pm 6,6$ & 0,001 & $32,91 \pm 6,5$ & 0,000 & & $37,0 \pm 5,5$ & 0,000 \\
\hline $21(5)$ & 58 & $32,8 \pm 7,0$ & & $40,1 \pm 6,3$ & & $35,2 \pm 6,4$ & & $30,2 \pm 8,3$ & & & $33,6 \pm 4,9$ & \\
\hline $22(6)$ & 12 & $28,5 \pm 3,6$ & & $35,5 \pm 5,7$ & & $39,8 \pm 7,8$ & & $29,8 \pm 9,3$ & & & $32,5 \pm 4,6$ & \\
\hline Sinıf & & & & & & & & & & & & \\
\hline 1 & 87 & $31,0 \pm 5,7$ & & $37,3 \pm 6,3$ & & $35,6 \pm 6,5$ & & $32,9 \pm 6,2$ & & & $35,2 \pm 5,4$ & \\
\hline 2 & 95 & $30,9 \pm 5,5$ & & $37,6 \pm 7,0$ & & $34,0 \pm 5,8$ & & $30,2 \pm 7,8$ & 7,331 & & $32,7 \pm 4,3$ & 20,611 \\
\hline 3 & 90 & $31,8 \pm 6,0$ & 2,047 & $38,0 \pm 6,8$ & 1,628 & $36,3 \pm 6,5$ & 5,672 & $32,1 \pm 7,0$ & 0,062 & & $36,3 \pm 5,6$ & 0,000 \\
\hline 4 & 124 & $32,2 \pm 6,7$ & 0,563 & $38,5 \pm 6,1$ & 0,653 & $36,0 \pm 6,8$ & 0,126 & $30,6 \pm 7,4$ & & & $34,5 \pm 5,2$ & \\
\hline Liderlik İle î & urumu & & & & & & & & & & & \\
\hline Evet & 84 & $36,0 \pm 7,7$ & 6,980 & $40,9 \pm 5,7$ & 8,451 & $39,2 \pm 6,7$ & 7,548 & $36,3 \pm 6,5$ & 11,386 & & $37,9 \pm 5,8$ & 7,410 \\
\hline Hayır & 302 & $30,3 \pm 4,9$ & 0,000 & $37,0 \pm 6,5$ & 0,000 & $34,5 \pm 6,0$ & 0,000 & $31,0 \pm 7,3$ & 0,151 & & $33,6 \pm 4,7$ & 0,000 \\
\hline Toplam & 386 & $31,5 \pm 6,1$ & & $37,9 \pm 6,5$ & & $35,5 \pm 6,5$ & & $31,0 \pm 7,2$ & & & $34,6 \pm 5,3$ & \\
\hline
\end{tabular}

Tablo 3'de çalışma grubunu oluşturan öğrencilerin bazı sosyo-demografik özelliklerine göre "Beş Faktör Kişilik Ölçeği'nden aldıkları puan ortalamaları dağııımı verilmiştir. Tablo 3 incelendiğinde, öğrencilerin "Beş Faktör Kişilik Ölçeği'nden "dışa dönüklük" alt boyutundan aldıkları puan ortalaması 31,5 $\pm 6,1$, "sorumluluk" alt boyutundan aldıkları puan ortalaması $37,9 \pm 6,5$, "duygusal denge" alt boyutundan aldıkları puan ortalaması $35,5 \pm 6,5$, "uyumluluk" alt boyutundan aldıkları puan ortalaması 31,0 $\pm 7,2$, "gelişime açıkık" alt boyutundan aldıkları puan ortalaması $34,6 \pm 5,3$ 'dir. İ̧̧letme bölümünde okuyan öğrencilerin yaş gruplarına göre "dışa dönüklük", "sorumluluk", "duygusal denge", "uyumluluk", "gelişime açıklık" alt boyutlarından puanları; cinsiyete göre "uyumluluk" alt alanı puanı; liderlik ile ilgili eğitim alma durumuna göre "dışa dönüklük", "sorumluluk", "duygusal denge", "gelişime açıklık" alt boyut puanları ve sınıfa göre "gelişime açıklık" alt boyut puanı yüksektir(her biri için; $p<0.05$ ). Ancak öğrencilerin cinsiyete göre "dışa dönüklük", "sorumluluk", "duygusal denge", "gelişime açıklık" alt boyutları puanları, sınıfa göre "dışa dönüklük", "sorumluluk", "duygusal denge", "uyumluluk" alt boyutlarının puanları arasında anlamlı bir farklılık saptanamamıştır(her biri için; $p>0.05$ ). 
Tablo 4: Öğrencilerin Cinsiyet, sınıf, yaş, liderlik eğitimi alma, Lider Stil Ölçeğinden Alınan Puanlar ile Beş Faktör Kişilik Ölçeği’nden Alınan Puanlar Arasındaki Korelasyon Analizi Sonuçları

\begin{tabular}{|c|c|c|c|c|c|c|c|c|c|c|c|c|}
\hline & 1 & 2 & 3 & 4 & 5 & 6 & 7 & 8 & 9 & 10 & 1 & 1. \\
\hline 1-Cinsiyet & 1 & & & & & & & & & & & \\
\hline 2-Sınıf & 022 & 1 & & & & & & & & & & \\
\hline 3- Yaş & ,112* & 918 & 1 & & & & & & & & & \\
\hline $\begin{array}{l}\text { 4-Liderlik eğitimi alma } \\
\text { Liderlik Stil Ölçeği }\end{array}$ &,- 032 &,$- 243^{*}$ &,$- 295 * *$ & & & & & & & & & \\
\hline 5- Liderlik Tarzı & ,044 & ,073 & 077 &,$- 278 *$ & & & & & & & & \\
\hline 6- Iliş̧ki tarzı & ,051 & ,136* & $*, 132 * *$ &,$- 313 *$ & $*, 962 *$ & $* 1$ & & & & & & \\
\hline 7- Görev tarzı & 037 & ,004 & ,011 &,$- 291 *$ & $*, 949 *$ & $*, 839 * *$ & $* 1$ & & & & & \\
\hline \multicolumn{13}{|c|}{ Beş Faktör Kişilik Anketi } \\
\hline 8- Uyumluluk &,$- 163 *$ & $*-, 079$ &,- 088 &,- 083 &,- 038 &,- 080 & ,009 & 1 & & & & \\
\hline 9- Dışa Dönük &,- 007 & ,084 & ,088 &,$- 387 *$ & $*, 262 *$ & $*, 289 * *$ & $*, 267 *$ & & 31 & & & \\
\hline 10- Sorumluluk &,- 076 & ,067 & ,095 &,$- 244 *$ & $*, 020$ & ,043 & ,028 & & 5,2 & $* * 1$ & & \\
\hline 11- Duygusal Denge &,- 075 & ,063 & ,059 &,$- 298 *$ & $*, 308 *$ & $*, 324 * *$ & *,298* & $*, 07$ & & **,168 & $* 1$ & \\
\hline 12- Gelişime Açıklık &,- 085 & ,025 & ,001 &,$- 329 *$ & *,180* & *,194** & $*, 213 *$ & $*, 05$ & 5 & $* *, 250$ & & $70 * * 1$ \\
\hline
\end{tabular}

$\mathrm{n}=386, * \mathrm{p}<.05, * * \mathrm{p}<.01$

Tablo 4 incelendiğinde, Öğrencilerin liderlik stil ölçeğinden alınan puanlar arttıkça $(r=0,962, p<0.01, r=0,949$, $p<0.01, r=0,262, p<0.01, r=0,308, p<0.01, r=0,180, p<0.01, r=0,839, p<0.01$ ), beş faktör kişilik ölçeğinden "dışa dönüklük, sorumluluk, duygusal denge, gelişime açıklık" dan alınan puanların artması $(r=0,289, p<0.01, r=0,324$, $p<0.01, r=0,194, p<0.01, r=0,267, p<0.01, r=0,298, p<0.01, r=0,213, p<0.01, r=0,218, p<0.01, r=0,363, p<0.01$, $r=0,315, p<0.01, r=0,168, p<0.01, r=0,250, p<0.01, r=0,370, p<0.01)$ istatistiksel olarak anlamlıdır. Yaş arttıkça ilişki tarzı liderlik stili puanları artarken $(r=0,132, p<0.01)$, yaş azalırken liderlik eğitimi alma durumu artmaktadır $(r=-0.295, p<0.01)$. Liderlik eğitimi almayanlarda hem genel hem de alt boyutları olan liderlik stil ölçeğinden alınan puanlar ( $r=-0.278, p<0.01, r=-0.313, p<0.01, r=-0.387, p<0.01, r=-0.291, p<0.01)$ ile beş faktör kişilik ölçeğinin alt boyutu "dışa dönüklük, sorumluluk, duygusal denge, gelişime açıklık"tan alınan puanlar artmaktadır ( $r=-0.291, p<0.01, r=-0.387, p<0.01, r=-0.244, p<0.01, r=-0.298, p<0.01, r=-0.329, p<0.01)$. 
Tablo 5: Kişilik Özelliklerinin Liderlik Davranışları Üzerine Etkisini Tanımlayan Yapısal Eşitlik Modelinden Elde Edilen Uyum Değerleri

\begin{tabular}{llllll}
\hline Uyum İndeksleri & Mükemmel Uyum & İyi Uyum & Uyumsuz & Elde Edilen Değer & Uyum \\
\hline $\mathrm{x}^{2} / \mathrm{df}$ & $0-2$ & $2-5$ & $>5$ & 2.37 & İyi Uyum \\
\hline $\mathrm{RMSEA}$ & $0-0.05$ & $0.05-0.10$ & $>0.10$ & 0.06 & İyi Uyum \\
\hline $\mathrm{NFI}$ & $0.90-1$ & $0.80-0.90$ & $<0.80$ & 0.95 & Mükemmel Uyum \\
\hline $\mathrm{CFI}$ & $0.90-1$ & $0.80-0.90$ & $<0.80$ & 0.97 & Mükemmel Uyum \\
\hline $\mathrm{GFI}$ & & & & 0.97 & Kabul \\
\hline
\end{tabular}

$\mathrm{x}^{2}$ : Minimum Fit Function Chi-Square ; $\mathrm{df}$ :Degrees of Freedom

RMSEA : Root Mean Square Error of Approximation; NFI: Normed Fit Index

CFI: Comparative Fit Index; GFI : Goodness of Fit Index

Geliştirilmiş olan teorik modelin uyum iyiliği; GFI, AGFI, RMSEA, $\chi^{2}$ ve $\chi^{2} / d f$ oranı ile belirlenmiştir. Kovaryansın bağıntı derecesini ve model tarafından ortaklaşa açıklanan varyansı GFI; 0.97 olarak saptanmıştır. AGFI uyum iyiliği değeri GFI'e benzer olarak 0.96 olarak saptanmıştır. Bu sonuçta GFI ve AGFI uyum iyiliği değerleri, teorik modelin elde edilen veriye uygun olduğunun göstergesidir. Diğer taraftan, RMSEA, model tarafından açıklanamayan varyans ve kovaryans ortalamasını içermekte ve çalışmada ise RMSEA değeri, 0.06 olarak saptanmıştır. Bu durumda, sadece birkaç varyans ve kovaryansın, oluşturan teorik model tarafından açıklanmamış olduğunu göstermektedir. Modelde her bir gizil değişkende açıklanan varyans, diğer gizil değişkenler ile ilişkisi sayesinde belirlenebilmektedir. Bu nedenle, her bir gizil değişkende açıklanan varyans ve bunun sonucunda belirlenen açıklanamayan varyans yani hata değerleri ölçme modelinin değil, daha çok yapısal modelin bir parçası olarak kabul edilebilirler. Çalışmada $\chi^{2} / d f$ oranı, 2.37 olması gözlenen ve çoğaltılan kovaryans matrisleri arasında iyi bir uyumun göstergesi anlamına gelmektedir.

Tablo 6: Kişilik Özelliklerinin Liderlik Davranışları Üzerine Etkisini Tanımlayan Ölçüm Modelinden Elde Edilen sonuçlar

\begin{tabular}{lllllll}
\hline Yapısal Eşitlik Modeli & & & Standardize $\boldsymbol{\beta}$ & S.H & t & $\boldsymbol{p}$ \\
\hline Liderlik Stil & $--->$ & Göreve yönelik & 9.940 & 3.110 & 3.196 & $\mathbf{0 . 0 0 1}$ \\
Liderlik Stil & $--->$ & iliş̧kiye yönelik & 1.238 & .099 & 12.492 & $<\mathbf{0 . 0 0 1}$ \\
Kişilik özelliği & $--->$ & Liderlik Stili & $\mathbf{8 . 7 8 7}$ & .550 & 5.671 & $<\mathbf{0 . 0 0 1}$ \\
Kişilik özelliği & $--->$ & Dışa dönüklük & 1.203 & .156 & 7.710 & $<\mathbf{0 . 0 0 1}$ \\
Kişilik özelliği & $--->$ & Sorumluluk & .686 & .145 & 4.742 & $<\mathbf{0 . 0 0 1}$ \\
Kişilik özelliği & $--->$ & Duygusal denge & 1.428 & .180 & 7.950 & $<\mathbf{0 . 0 0 1}$ \\
Kişilik özelliği & $--->$ & Uyumluluk & .050 & .152 & .330 & 0.741 \\
Kişilik özelliği & $--->$ & Gelişime açıklık & 9.423 & 1.755 & 11.070 & $<\mathbf{0 . 0 0 1}$ \\
\hline
\end{tabular}

Oluşturulan YEM sonucuna göre; kişilik özelliği liderlik stilini 8.78 puan arttırmaktadır. 


\section{Şekil 1: Kişilik özelliklerinin liderlik davranışları üzerine etkisini tanımlayan yapısal eşitlik modeli}

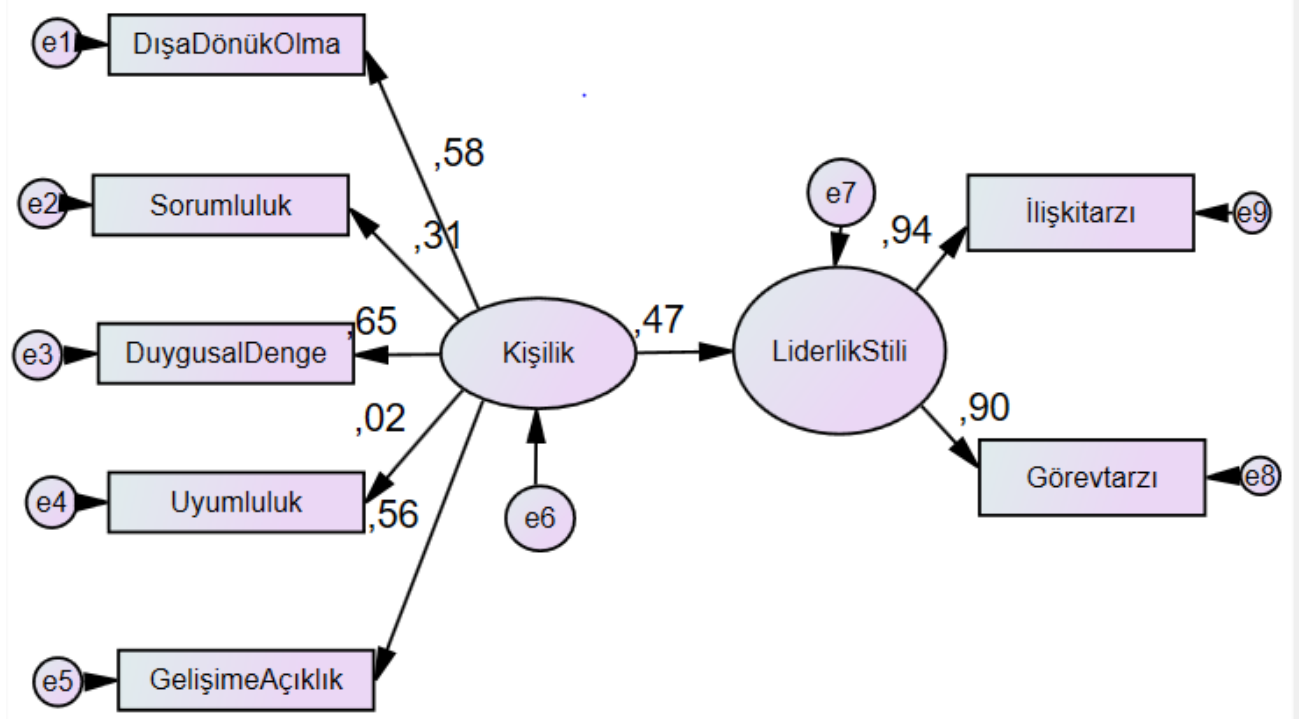

Elde edilen bulgulara göre, Kişilik özelliklerinin liderlik stil davranışları üzerine direk etkisini gösteren Path katsayıları istatistiksel olarak anlamlı bulunmuştur. Bunlar sırasıyla; dışa dönüklük .58, sorumluluk .31, duygusal denge .65 , gelişime açıklık .56’dır. Beş faktör kişilik özelliğinin liderlik stil davranışına etkisi .47'dir. Liderlik stili ilişki tarzı liderliğe etkisi .94 iken görev tarzına etkisi .90’dır. Buna karşın, bu parametreler dışında kalan tüm parametrelerin istatistiksel olarak anlamsız olduğu saptanmıştır.

\section{SONUÇ}

İşletmelerin hayatta kalabilmesi için insan gücü ve günümüz rekabet piyasası çok önemlidir. İşletmeleri amacına ulaştıracak olan insan gücünün yönlendirilmesi ve motive edilmesi liderlik stili ile yakından alakalıdır. Uygun liderlik tarzının seçilememesi çalışanların motivasyonlarının düşmesine ve işletmelerin amaçlarına ulaşmada sıkıntılar yaşamasına sebep olmaktadır.

Kişiliğin liderlik üzerindeki etkisini araştıran çalışmalar, başlangıçta tutarlı bir biçimde belli bir kişilik özelliğinin liderliğe etkisini bulamazken, özellikle beş faktörlü kişilik testi ile yapılan liderlik araştırmaları bu iki değişken arasında tutarlı bir ilişkinin varlığını tespit etmiştir(Lita \& Grigoraş, 2007; Taşdöven, Emhan, \& Dönmez, 2012). Deneysel bulgularla desteklenmemekle birlikte, etkili liderlerin başlıca kişisel özelliklerinin duygusal istikrarlılık, inisiyatif kullanma, başarı isteği ve girişkenlik olduğu iddia edilmiştir(Stogdilll, 1974).

Yapılan bazı çalışmalar incelendiğinde, 2005 yılında Dumlupınar Üniversitesi’nde yapılan bir araştırmada Eczacıbaşı Topluluğundaki 100 adet yöneticinin kişilik tarzları ile liderlik davranışları arasındaki ilişki incelenmiştir. Bu anket çalışması sonucunda kişilik tarzları ile liderlik davranışları arasında anlamlı bir ilişki bulunmuştur(Giderler, 2005).

2007 yılında yapılan bir araştırmada 2006-2007 öğretim yılında eğitim gören son sınıfa ait 190 Deniz Harp Okulu öğrencisinin liderlik profilleri ve kişilik tipleri incelenmiştir. Bu çalışmada öğrencilerin liderlik tarzları ile kişilik tiplerinin birbirinden bağımsız olduğu sonucuna varılmıştır(Sağlamkardeş, 2007).

2012 yılında Celal Bayar Üniversitesi'nde yapılan bir araştırmada Polis Teşkilatı çalışanlarının liderlik tarzı ve mizaç-karakter ilişkisi incelenmiştir. Bu anket çalışmasında yapılan analizler sonucunda, kişilik ve liderlik arasında anlamlı istatistiki bir ilişki bulunmuştur(Taşdöven et al., 2012).

2013 yılında Hamideh Ojaghi Shirmard, Seyed Mahmood Mirzamani, Abbas Khorshidi tarafından yapılan araştırmada 2011-2012 eğitim öğretim döneminde Islamshahr'daki 74 okulun müdürlerinin kişilik tipleri ve liderlik tarzları arasındaki ilişki incelenmiştir. Bu araştırmanın sonucunda kadın ve erkek arasında kişilik tipleri ve liderlik stilleri arasındaki ilişki açısından önemli bir fark olmadığı, kadınların erkeklere göre daha gerçekçi kişilik 
tipine sahip olduğu, görev yönelimli liderlik tarzında kadın ve erkek arasında anlamlı bir farklılık olduğu, muhafazakar kişilik tipi ile acil durum liderlik tarzı arasında anlamlı bir ilişki olduğu sonucuna ulaşılmıştır(Shirmard, Mirzamani, \& Khorshidi A., 2013).

2008 yılında Magister Theologia tarafından yapılan araştırmada Pentecostal Kilisesi liderlerinin kişilik tiplerinin liderlik davranışlarına olan etkisi incelenmiştir. Araştırma bulgularının sonuçlarına göre kilise liderlerinin kişilik tiplerinin liderlik tarzları üzerinde önemli bir etkisi olduğu ortaya konulmuştur (Theologia, 2008).

2012 yılında Mohammadreza Bahreinian ve Mohamadali Ahi tarafından yapılan araştırmada yöneticilerin kişilik tipi ve liderlik tarzı arasındaki ilişki incelenmiştir. Elde edilen sonuçlar yöneticilerin liderlik tarzlarının büyük ölçüde kişiliğin öğelerine doğrudan bağlantılı olduğunu göstermiştir(Bahreinian, 2012).

2013 yılında Oral tarafından yabancı bir ilaç şirketinin yöneticilerinin örneklem olarak seçildiği araştırmada kişilik özellikleri ile liderlik tarzı arasında kısmen ilişki bulunmuştur(Oral, 2013).

Liderin kişilik özellikleri, hangi liderlik türünün daha etkili olduğu, sahip olması gereken yönetim tarzı, astlarına yaklaşımı, liderin ekip içindeki pozisyonu gözler önüne serilirken, etkili olmayan liderlik davranışı üzerinde yeterince durulmadığı görülmektedir(Gündüz \& Dedekorkut, 2014, p. 96).

Stil yaklaşımı liderin davranışına vurgu yapar. Bu da onu liderin kişilik özellikleri üzerinde duran kişilik yaklaşımından ve liderin yetenekleri üzerinde duran beceriler yaklaşımından ayırt eder. Stil yaklaşımı davranışı görev ve ilişki boyutlarıyla değerlendirilerek liderliği geniş bir şekilde değerlendirmek için önemli bir çerçeve sunar. Bu çerçeve öğrenilerek liderlik davranışları edinilebilir ve geliştirilebilir. İşletme öğrencilerinin kişilik özellikleri ve liderlik davranışları ile ilgili algısı geleceğin liderliğini anlamamıza ışık tutacağı için literatüre önemli katkı sağlayacağı düşünülmektedir.

Araştırmamızdan elde edilen bulgulara göre kişilik özelliklerinin liderlik davranışı eğilimine etkisi olduğu tespit edilmiştir. Yapılacak yeni araştırmalarda bu etki düzeylerinin benzerlik ve farklılıkların bulunması önem taşımaktadır. Kişilik özellikleri ve algılanan liderlik davranışlarını belirlenmesi, ülkemizin insan gücünün yönlendirilmesi ve sonuçlarının değerlendirilmesi sorunlarımızın çözümünde etkili olacağı düşünülmektedir.

\section{KAYNAKLAR}

Allport, G. (1921). Kişilik ve Karakter. Psychological Bulletin, 18, 441-455.

Bahreinian, M., Ahi, M. (2012). The Relatıonshıp Between Personality Type And Leadership Style Of Managers. A Case Study. Mustang Journal of Business \& Ethics, 3, 94-111.

Bakan, İ., \& Büyükbeşe, T. (2010). Liderlik Türleri ve Güç Kaynaklarına Illişkin Mevcut Gelecek Durum Karşılaştırması: Eğitim Kurumu Yöneticilerinin Algılarına Dayalı Bir Alan Araştırması. KMÜ Sosyal ve Ekonomik Araştırmalar Dergisi, 12(19), 73-84.

Barrick, M., Day, D., Lord, R., \& Alexander, R. (1991 ). Assessing the utility of executive leadership. The Leadership Quarterly, 2(1), 9-22.

Bass, B. M. (1990). Bass and Stogdill's Handbook of Leadership, (3.Edition ed.). New York: The Free Press.

Burke, W. W., \& Litwin, G. H. (1992). A Causal Model of Organizational Performance and Change. Journal of Management, 18(3), $523-545$. doi:10.1177/014920639201800306

Cook, K. C., Hunsaker, W. P. L., \& Coffey, R. E. (1997). Management and Organizational Behavior. Chicago: Irwin. TheMcGrawHilliBook. Companies, Inc.

Çelik, C., \& Sünbül, Ö. (2008). Liderlik Algılamalarında Eğitim ve Cinsiyet Faktörü: Mersin illinde Bir Alan Araştırması. Süleyman Demire Üniversitesi Iktisadi ve Idari Bilimler Fakültesi Dergisi, 13(3), 49-66.

Giderler, C. (2005). Yöneticilerin Kişilik Tarzları ile Liderlik Davranışları Arasındaki İlişki ve Ezcacıbaşı Topluluğu'nda Uygulama. (Yüksek Lisans Tezi.), Dumlupınar Üniversitesi, Kütahya.

Gündüz, Y., \& Dedekorkut, S. E. (2014). Yıkıcı Liderlik. Mersin Üni. Eğitim Fakültesi Dergisi, 10(1), 95-104.

Hodgetts, R. M. (1999). Yönetim Teori, Süreç ve Uygulama (C. Çetin \& E. C. Mutlu, Trans. 5 ed.). İstanbul: Der Yayınları.

Hogan, R., Curphy, G. J., \& Hogan, J. (1994). “What We Know about Leadership: Effectiveness and Personality. AmericanPsychologist,, 49(6), 493-504.

İnanç, Y. B., \& Yerlikaya, E. E. (2008). Kişilik Kuramları. Ankara: Pegem Akademi. 
Judge, T. A., Piccolo, R. F., \& Kosalka T. (2009). The Bright and Dark Sides of LeaderTraits: A ReviewandTheoretical Extension of the Leader Trait Paradigm. The Leadership Quarterly,, 20, 855-875.

Koçel, T. (2001). Iş̧letme Yöneticiliği (8 ed.). İstanbul: Beta Basım Yayım Dağıtım A.Ş.

Kognor, H., \& Nordvik, H. (2004). PersonalityTraits in Leadership Behavior. Scandinavian Journal of Psychology, 49-54.

Lita, C. Ş., \& Grigoraş, M. (2007). The Role of PersonalityTraits in PoliceLeader'sBehavior. . Paper presented at the The 1st Symposium of Pedagogy and Psychology.

Northouse, P. G. (2013). Leadershhip: Theory and practice (6 ed.). Thous and Oaks. : CA: SAGE Publications Inc.

Oral, O. (2013). Yöneticilerin Kişilik Tarzlarının Liderlik Davranışlarına Etkisi: Yabancı Ilaç Firma Uygulaması. (Yüksek Lisans Tezi), Beykent Üniversitesi, ìstanbul.

Özmen, H. I. (2009). Liderlik Davranışını Etkileyen Toplumsal Normların Analizi. (Doktora), T.C.Süleyman Demirel Üniversitesi Isparta.

Sağlamkardeş, H. (2007). Deniz Harp Okulu Son Sını Öğrencilerinin Liderlik Profilleri ve Kişilik Tipleri Analizi. (Yüksek Lisans ), Deniz Harp Okulu, ìstanbul.

Shirmard, H. O., Mirzamani, S. M., \& Khorshidi A. (2013). The Relationship Between Personality Types and Leadership Styles of High. Iran. Stogdilll, R. M. (1974). Handbook of Leadership. New York: FreePress.

Strang, S. E., \& Kunhert, K. W. (2009). Personality and Leadership Developmental Levels as predictors of Leader performance. . The Leadership Quarterly, 1-13.

Taslak, S. (2008). Göreve Ilişkin Çatışmalarda Etkileşimci ve Dönüşümcü Liderlik Üzerine Etkisel Bir Değerlendirme. Erciyes Üniversitesi iktisadi ve Idari Bilimler Fakültesi Dergisi, 31, 121-144.

Taşdöven, H., Emhan, A., \& Dönmez, M. (2012). Liderlik Tarzı Ve Mizaç-Karakter Iliş̧kisi: Polis Teşkilatında Bir Uygulama. Celal Bayar Üniversitesi I.i.B.F. Yönetim ve Ekonomi Dergisi, 19(2), 165-177.

Tatılııoğlu, K. (2014). Üniversite öğrencilerinin beş faktör kişilik kuramı́na göre kişilik özellikleri alt boyutlarının bazı değişkenlere göre incelenmesi. Tarih Okulu Dergisi (TOD) Journal of History School (JOHS), 7(XVII), 939-971. doi:http://dx.doi.org/10.14225/Joh400

Thelogia, M., (2008). LeadershipStylesAndPersonalityTypes. South AfricanTheologıcalSeminary.

Werner, I. (1993). Liderlik ve Yönetim (V. Üner, Trans.). İstanbul: Rota Yayınevi. 